\title{
On Mimi
}

\begin{abstract}
The paper addresses the, as of yet, unresolved issue of the genetic affiliation of the so-called "Mimi" languages - two separate idioms recorded more than a hundred years ago in the Wadai-Darfur region of Northern Africa (a third idiom that also used to be called "Mimi" has already been uncontroversially demonstrated as a close relative of the much better known Fur language). Although many researchers, following J. Greenberg, have generally settled on affiliating both of these languages with the Maba group, a close analysis of available lexical data, with emphasis on the internal distribution and etymologization of proposed Maba cognates, shows that only one of the two idioms ("Nachtigal's Mimi") yields enough evidence to accept its (somewhat distant) relation to Maba as a working hypothesis. Relations of the other idiom, "Decorse's Mimi", with the Maba group, on the other hand, should more reasonably be interpreted as areal, with the language's genetic provenance remaining somewhat of a mystery; this particular issue will most likely remain unresolved until a better understanding of the internal classification of the Nilo-Saharan macrofamily is gained.
\end{abstract}

Keywords: Nilo-Saharan languages, Mimi language, Maba languages, lexicostatistics, language taxonomy, comparative method, language relationship, Swadesh wordlist.

\section{General information}

Over a period spanning around a hundred years, data from at least three different languages have been recorded as representing the speech of a tribe or a number of tribes called "Mimi", located around the Wadai-Darfur region. As of now, two of these are most probably extinct (at least, no new data have surfaced since the original attestation), leaving behind the problem of determining their genetic affiliation based on relatively scant and, quite likely, inadequately transcribed lexical data.

Chronologically, the first linguistic records on a "Mimi" language were made by Gustav Nachtigal around 1870 during his ethnographic work in Eastern Sahara; they remained unpublished for more than half a century, before finally emerging as [Lukas \& Völckers 1939]. Thirty-plus years later, another wordlist, collected by G. J. Decorse, was published in M. Gaudefroy-Demombynes' survey work on several languages of the Ubangi-Shari area [Gaudefroy-Demombynes 1907: 322-329].

Although both of these publications allegedly dealt with the same "Mimi", it very soon became clear that the two lists could hardly belong to two different dialects of the same language or, indeed, even two different, but closely related languages. A. N. Tucker, in particular, remarked that "the linguistic material (vocabularies) collected by these two authorities... shows remarkably little correspondence" [Tucker \& Bryan 1956: 53], and refrained from any attempts at classification.

J. Greenberg initially noted what seemed to be significant lexical resemblances between "Decorse's Mimi" (Mimi-D) and what was then known of the Maba ${ }^{1}$ group of languages, geo-

\footnotetext{
${ }^{1}$ Maba, or Maban, languages, spoken in Wadai-Darfur, should by no means be confused with Mabaan, a language uncontroversially affiliated with the Western Nilotic family (the confusion has, unfortunately, perpetrated

Journal of Language Relationship • Вопросы языкового родства • 6 (2011) • Pp. 115-140 • Starostin G., 2011
} 
graphically contiguous with "Mimi"-speaking areas; he was, however, far more reserved about any such links with "Nachtigal's Mimi” (Mimi-N) [Greenberg 1950]. Nevertheless, by the time that his African classification was finalized, he was already feeling more secure in that department as well; the Maban group, as a primary constituent of his "Nilo-Saharan"2 macrophylum, consists of such "properly Maban" languages as Maba and Runga and also includes both Mimi-D and Mimi-N [Greenberg 1966: 130]. However, Greenberg does point out that Mimi-D is much closer to "proper Maban" than Mimi-N [Greenberg 1971: 426], which would seemingly explain his original hesitation.

In the meantime, a third "Mimi" had surfaced, in the form of some brief fieldnotes taken by H. Jungraithmayr in Abeche in 1959. Having compared these findings with the previously published lists of Mimi-N and Mimi-D, Jungraithmayr concluded that all three idioms must represent different languages, even mentioning the possibility of a fourth "Mimi" (unpublished materials collected by van Bulck and mentioned by name in [Tucker \& Bryan 1956: 53]) [Jungraithmayr 1971].

This particular confusion, fortunately, was cleared up almost immediately: already the next year after the publication of Jungraithmayr's data, they were analyzed by Greenberg, who demonstrated, quite uncontroversially [Greenberg 1972], that "Jungraithmayr's Mimi" had nothing to do with either Mimi-N or Mimi-D or Maban languages, but represented a separate idiom that was closely related to the well-known and widespread Fur language. Greenberg suggested renaming the third "Mimi" to Biltine, in accordance with the region in which the language was spoken, but the more common term today is Amdang (the autonym of the speakers). Since then, even more data have emerged on "Jungraithmayr's Mimi" / Biltine / Amdang - first, a slightly more detailed wordlist collected by P. Doornbos (published as part of the survey work [Doornbos \& Bender 1983]), and then, quite recently, a 220-item wordlist collected, as part of an SIL survey, by Katharina Wolf in four different Amdang-speaking villages [Wolf 2010]. All of these publications further confirm Amdang's close relationship with Fur, transforming the former "language isolate" into a two-language family, much to the delight of the comparative-historical linguist (although proper historical research on the Fur-Amdang group is still seriously impeded by lack of data). This matter may, therefore, be considered as settled, and we will exclude the "third Mimi" from further scrutiny", concentrating exclusively on the issue of "Mimi-N" and "Mimi-D".

Although J. Greenberg seemed to have relatively little trouble grouping Mimi-D together with Maban (and only moderately bigger trouble grouping Mimi-N with the same), it must be taken into account that the lexical data on Maban, based on which any taxonomic conclusions could have been drawn at the time, was exceedingly scarce. The only Maban language to boast at least a moderately comprehensive grammatical description and vocabulary was Maba itself,

all of the recent versions of the Ethnologue, e. g., [Ethnologue 2009], in which all of the Maba languages are erroneously listed as constituting part of the Maban-Burun subbranch of Western Nilotic). To avoid further confusion, below we will reserve the name Maban for the entire group and Maba for its most widespread and best studied member.

2 I enclose the term "Nilo-Saharan" in quotation marks, here and (for the most part) below, since, as of now, I am not yet fully convinced of the historical reality of this macrofamily within those particular borders that are assigned to it by most of its proponents (J. Greenberg, H. Fleming, L. Bender, Ch. Ehret and others); hopefully, active etymological and lexicostatistical research on language groups that supposedly constitute "Nilo-Saharan", with the aid of new data, new methods, and new specialists, over the next few years (decades?) will help clarify the issue.

${ }^{3}$ The mysterious "fourth Mimi", recorded by van Bulck, still known only by its name, is quite likely to be the same as the "third Mimi" (Amdang), considering that the autonym of the speakers, according to van Bulck, is also recorded as anday-ti [Tucker \& Bryan 1956: 53]. 
due to its significant sociolinguistic stature in the Wadai region; the main works consulted were a monograph by G. Trenga [1947] and a series of papers by J. Lukas on various aspects of Maba phonology and morphology [Lukas 1933, 1952], including a brief collection of published texts [Lukas 1953].

Apart from Maba proper, the only other Maban group language known to Greenberg (and even then, quite tangentially), words from which can be occasionally encountered in his list of Nilo-Saharan comparanda in [Greenberg 1966: 133-148], was Runga (better known today as Aiki). However, Greenberg's main source on this language was nothing more than yet another scant wordlist (186 entries) collected by Decorse and made accessible in the same publication [Gaudefroy-Demombynes 1907] that also yielded the lexical data on Mimi-D. It may be assumed that the remaining scraps of data, such as, e. g., R. Stevenson's officially unpublished records of Masalit (mentioned in [Tucker \& Bryan 1956] and partially revealed in [Tucker \& Bryan 1966: 193-205]), were unknown to Greenberg at the time that he was working out his African classification, since none of them can be found quoted in [Greenberg 1966].

Thus, both Mimi-N and Mimi-D were basically aligned together with Maban, known today as a rather extensive, if still poorly described, language family, on the strength of their lexical resemblances (grammatical data is, unfortunately, unknown on either of the two Mimis) with Maba proper and little else. In the light of Maba's rather strong linguistic domination in the described region, this, in retrospect, would seem to be somewhat premature: no special attempt had been made to ensure that the observed resemblances were indeed more likely to reflect common genetic origin than a strong areal influence exercised by Maba on the two Mimis. Indeed, no such attempt was possible: J. Greenberg was establishing what essentially amounted to a simple binary connection (minimal available information on Runga notwithstanding), and, with limited data on the Maban side and pitifully limited data on the Mimi side, no proper comparative-historical research on the subject could be carried out by anyone.

In recent decades, however, the situation has changed quite drastically. Although, unfortunately, no new data on either of the two Mimis has surfaced, much has been done to improve our knowledge of the Maban family. Regarding particular languages, Aiki (Runga) has now been given the monograph treatment by P. Nougayrol (grammatical description and midsize vocabulary in [Nougayrol 1989]), and he has also published a shorter, but quite informative paper on one of Aiki's close relatives, Kibet [Nougayrol 1986]. Masalit is now better understood due to work by J. Edgar, also published as a monograph [Edgar 1989]. New data have been published on Maba as well.

The most important publication of all, however, was J. Edgar's impressive attempt at putting together a comparative lexicon of all varieties of Maban languages [Edgar 1991a] that included data not only from published sources, but numerous hitherto inaccessible manuscripts and fieldwork collections as well. This achievement finally enables researchers to conduct more or less proper comparative-historical work on Maban, and Edgar himself was the first to capitalize on his systematization of the data, coming up with a general classification as well as a preliminary reconstruction of the phonological system of Proto-Maban [Edgar 1991b]. Unfortunately, the latter paper was published already after Edgar's death in April 1991, and since then, very little has been done to continue his research. This means that, if we really want to reassess the issue of Mimi-N and Mimi-D's relationship with Maban, any new analysis of formerly observed lexical resemblances will involve at least a small amount of historical research into the comparative phonology, semantics, and distributional characteristics of the Maban etyma.

To the best of my knowledge, there have only been two attempts at re-evaluating the "Mimi problem" since its tentative solution offered by Greenberg. The first one is to be found 
in the general survey work by P. Doornbos and M. L. Bender [1983], who reproduce some parts of the Mimi-N / Mimi-D wordlists and, upon comparing them once again with Maban, tend to agree with Greenberg's classification, although the genetic relationship between Mimi and Maban is seen as a relatively remote one. Based on a selection of 26 lexical items, the authors indicate that Mimi-D shares approximately 9 "cognates" with Maban languages, whereas for Mimi-N the figure oscillates between 2 and 5; furthermore, there are no more than 2 comparable items between Mimi-D and Mimi-N themselves, excluding any possibility of grouping them in a single taxon. However, Doornbos \& Bender's lexical selections are not numerous enough to be truly representative and reliable; moreover, they make no analysis of the distribution of the respective "corresponding" forms within the Maban family, essentially leaving the question of "contact vs. relationship" wide open.

J. Edgar, in his comparative vocabulary of Maban languages, had faithfully added all of the Mimi-N and Mimi-D material, without any definitive statements on whether these languages should really be included into Maban genetically or not; according to him, "they remain somewhat mysterious linguistically" [Edgar 1991a: 14]. He is being a little more precise in [Edgar 1991b: 114]:

“...it seems clear from the limited amount of data available that the Mimi lists of Decorse (in GaudefroyDemombynes 1906) belong to a Maba-group language, though this needs further investigation. The Mimi lists of Nachtigal (Lukas und Völkers 1938/39) have been renamed Biltine and reclassified as part of the Fur group. As far as I know, Jungraithmayr's (1971) Mimi remains a mystery”.

There is an obvious and, most likely, accidental mix-up here: the lists that "have been renamed Biltine" are, in fact, Jungraithmayr's, whereas the Mimi that "remains a mystery" is Nachtigal's. With that correction in mind, Edgar's position is, in fact, identical to Doornbos \& Bender's: Mimi-D is likely to be a remote relative of Maban, Mimi-N is just as likely to be not, observed resemblances stemming from occasional contact or simple coincidence. However, Edgar's opinion seems to have rather been molded by the earlier research of Greenberg and Bender than by his own comparisons: in the comparative lexicon, occasional Mimi items are grouped together with Maban forms based on general phonetic resemblance alone, and no Mimi data have been used to work out the historical phonology of Maban in [Edgar 1991b].

Subsequent works on Nilo-Saharan in general have avoided discussion on the status of the two Mimi languages. In his detailed description of the macrofamily, Bender [1997: 23] simply ties both of them in with Maban without any comments, and Ehret [2001: 88] simply lists "Mimi" as part of Maban without even specifying that there are, in fact, two Mimis (closer scrutiny of the comparative data in his dictionary indicates that he does draw a distinction, quoting exclusively or, at least, almost exclusively from Mimi-D).

In the light of all this, it is clearly high time that the issue be reopened once more, if only for the reason that no one, so far, has taken serious advantage of our significantly improved knowledge of Maban languages and our ability to assess their data from a historical point of view, in order to verify earlier hypotheses on Mimi.

\section{Methodology of investigation}

Considering that almost no grammatical information is available on either of the Mimis, and that the lexical lists are relatively short, it would make sense to scrutinize all of the available information. That way, however, we run a serious risk of picking up disruptive "noise" in 
the form of lexical borrowings. In order for our findings to be somewhat conclusive, it is necessary to apply what I call the principle of dynamic lexical gradation: range compared lexical items from the ones that are empirically known to be more stable and resistant to borrowing ("basic") down to those that are more likely to be borrowed under conditions of cultural pressure from the "dominant" language (such as Maba could have been to any of the two Mimi lects). Naturally, in order to demonstrate a high probability of relationship, there must be more matches between the compared languages within the "stable" subset of their wordlists than the "unstable" one.

In practice, the dynamic gradation principle will be enforced as follows. First, we will concentrate exclusively on the "basic lexicon" as represented by the standardized Swadesh list, assuming that, if the relationship cannot be substantiated based on these particular items (of which quite many, if not all, are found among the data on both Mimis), it cannot be demonstrated at all - a principle that holds well for all of the world's language families without a single exception. Second, we will be dividing the wordlist in two halves based on the average "index of stability" for individual items, calculated in [S. Starostin 2004] and slightly modified for matters of technical convenience in [Starostin 2010]. Primary attention will be paid to the first 50 items on the list, which will be compared - where possible - with their Maban equivalents on phonetic, semantic, distributional and lexicostatistical grounds. Once certain preliminary conclusions have been reached based on this analysis, they may be further strengthened by other kinds of lexical evidence, both in this paper and future studies.

Before proceeding, it is necessary to provide some brief information on the internal classification of Maban, since the family's tree structure is of vital importance for any external comparison of its data with that of Mimi (or, in fact, any other languages of Africa). My lexicostatistical analysis, based on cognate establishment by means of the comparative method (rather than just phonetic similarity), yields the following matrix (transparent recent borrowings are excluded from calculations):

\begin{tabular}{l|cccc}
\hline & Kodoi & Masalit & Aiki & Kibet \\
\hline Maba & $96 \%$ & $67 \%$ & $52 \%$ & $56 \%$ \\
Kodoi & & $66 \%$ & $50 \%$ & $54 \%$ \\
Masalit & & & $58 \%$ & $57 \%$ \\
Aiki & & & & $85 \%$ \\
\hline
\end{tabular}

which may be easily correlated with the following tree structure:

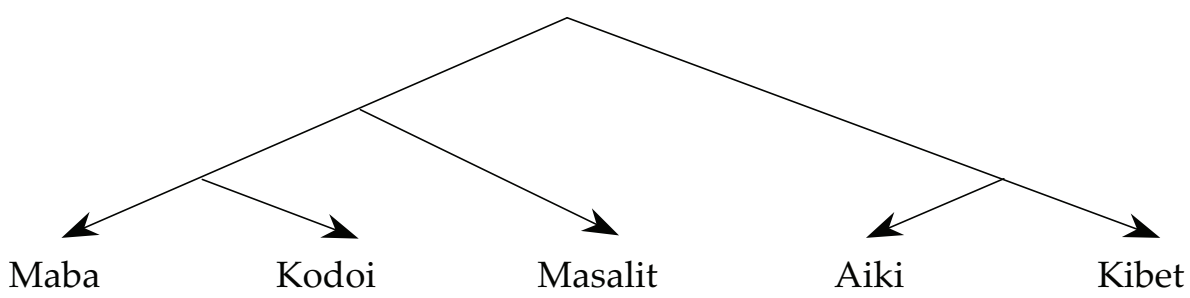

The matrix confirms Kodoi (originally known only through a brief wordlist in [GaudefroyDemombynes 1907], later described much more thoroughly due to P. Doornbos' fieldwork, with most of the results published in [Edgar 1991a]) as merely a dialect of Maba proper, and also supports the universally accepted common grouping of Aiki and Kibet (below we will use the tradi- 
tional term "Kibet-Runga" to denote this branch). Lexicostatistics also shows that the Masalit language is considerably closer to the Maba dialect cluster than to Kibet-Runga, an argument in favor of a primary binary branching into "Kibet-Runga", on one hand, and "Maba-Masalit", on the other. This differs from the results of J. Edgar [1991b], who, based on P. Nougayrol's wordlist of 115 items (significantly different from the Swadesh list), was not able to perceive a closer affinity between Maba and Masalit than between Maba and Kibet-Runga and, consequently, postulated an original tripartite division, in which the Kibet-Runga cluster was considered "South Maban", the Masalit cluster was "Central Maban", and Maba-Kodoi was "North Maban". However, Edgar obviously did not consider the disturbing effect of loanwords, and, furthermore, quite a few of his cognate judgements, as his work on Proto-Maban shows, are debatable.

The bipartite scheme, presented here, is liable to further corrections as more data on the languages (particularly such poorly described dialectal varieties as Marfa, Karanga, Baxat etc.) become available, but, judging by the distribution of basic cognates, it is unlikely that the Maba-Masalit branch will be invalidated: it is tightly held together by such important MabaMasalit vs. Kibet-Runga isoglosses as 'fire', 'fat (n.)', 'foot', 'heart', 'meat', 'mouth', 'tree', and others - isoglosses that single out Maba, on the other hand, are few and far between, and some of them, as will be shown below, can actually be ascribed to external influence upon Maba (e. g. 'dog'). Thus, the bipartite division will be assumed as our working hypothesis in the ensuing analysis, with a direct bearing on some of the conclusions.

One important, essentially non-disputable, presumption is that Mimi-N and Mimi-D may or may not be genetically related to Maban, but they most definitely cannot be related more closely to any particular subbranch of Maban, except through convergence (contact). Had this been the case (e. g. Mimi-D as part of the Maba-Masalit branch, and Mimi-N as part of the KibetRunga branch), the relationship would have been obvious from the very start, and there would have been no need for writing this paper in the first place. We are clearly testing the "elder brother" hypothesis here - namely, that the Mimis simply branched off the "Pre-Proto-Maban" stem before the bipartite division of Maban into Maba-Masalit and Kibet-Runga, i. e. the possibility of whether any of the Mimis could not be the "Anatolian" taxon to Maban's "IndoEuropean". Incorporation of one or both of the Mimis within Maban, based on available data, is impossible (and it is hard to imagine how it could be possible even if new data were to surface).

The following abbreviations are used below: (a) for language names: Aik = Aiki, Kib = Kibet, Kod = Kodoi, Mab = Maba, Msl = Masalit, D = Mimi-D = Decorse's Mimi; N = Mimi-N = Nachtigal's Mimi; (b) for sources: [Cp.] = data collected by J.-P. Caprile, in [Edgar 1991a]; [Db.] = data collected by P. Doornbos, in [Edgar 1991a]; [Ed.] = data collected by J. Edgar, in [Edgar 1989, 1991a, 1991b]; [Lk.] = data collected by J. Lukas, in [Edgar 1991a; Lukas 1933, 1952, 1953]; [Ng.] = data collected by P. Nougayrol, in [Nougayrol 1986, 1989]; [Tr.] = data on Maba, in [Trenga 1947]. All of the data on Kodoi are from P. Doornbos' fieldwork, published in [Edgar 1991a] and, consequently, remain unmarked.

\section{0-item wordlist for "Mimi" with comparative analysis}

1. ashes: Not attested in either of the two Mimis.

2. bird: N kabal-a ka:wal-a (pl. kawal); not found in D.

The $\mathrm{N}$ word is clearly connected with the Maba word for 'bird' as attested in the early dictionary of H. Barth: kebél, pl. kebél-ne [Barth 1862: 201], and is also found in J.-P. Caprile's field data as kèbbél. However, this is quite clearly not the primary designation for 'bird' in the 
group as a whole: that honor belongs to the stem *kuši $(-k) \rightarrow$ Mab kǔší-k [Cp., Db.], kuši $k$, kušak [Ed.], Kod ku:šî-k, Msl kúší-k, kú:či [Ed.], kúčì [Db.], Aik kj̀súi [Db.], kòsí [Ng.], Kib kj̀sí [Db.], $k w o ̀ s i ́$ [Ng.] (reconstruction of the vocalism is approximate).

On the other hand, forms with the meaning 'bird' and the general syllabic structure of ${ }^{*} k V b V l V \sim * k V b V r V$ are found quite frequently in the "Nilo-Saharan" area: cf. such examples as Dongolese Nubian kawirte, Murle (Surmic) kiballe-či, Teda-Daza *kefuri and many others. Without jumping to conclusions about how much of this diversity is due to genetic or areal connections, we may simply point out that *kebelV *kabalV, due to lack of its attestation in any language other than Maba, is not reconstructible in the meaning 'bird' for the entire group (in fact, it is not reconstructible in any meaning at all), and that Mimi-N kabal-cannot be used as first-order evidence for a genetic relationship with Maban languages.

\section{3. black: D liwuk; not found in N.}

The obvious parallel in this case is the main word for 'black' in Maba: Mab lulio- $k$, lilio- $k$ [Ed.], lùlyó-k [Db.], Kod lulîyó- $k$ [Db.]. Again, however, the Maba word is isolated in Maban, and there are two other details that place its archaic nature under doubt: first, the considerable rareness of initial * $l$ - in Proto-Maban as a whole, second, the rather wide areal distribution of such forms as *lu(y), *lul with the easily compatible semantics of 'black', 'dark', 'night' etc. in geographically close languages (cf., in particular, Tama luygni 'black' and Fur lù.l 'night').

On the other hand, the Maba word certainly exhibits behavior that is typical of "genuine" Maba adjectives denoting colors, cf. kùkúyà-k 'red', fáfárà-k 'white', drìdríya-k 'green' etc. Another counter-argument concerns distribution: even if the Maba word has no parallels in the rest of the group, it can still potentially qualify for Proto-Maba status, since all the major

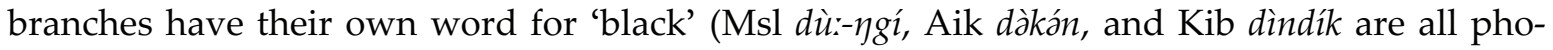
netically similar, but cannot be reduced to a single proto-stem).

Subsequently, it is possible to suggest either genetic or areal relationship between Mimi-D liwuk and Maba lulio-k (in the latter case, we would have to assume that the borrowing was made into Mimi-D before the word was reduplicated in Maba).

4. blood: $\mathrm{N}$ ari (pl. ari-si:); not found in D.

The $\mathrm{N}$ word is an exact phonetic match with the primary Maba word for 'blood': Mab cri [Tr.], àrí: [Cp.], Kod arî.: The internal Maban etymology of this item is, however, problematic. The rest of the languages reflect a very similar form, but with initial f-: Msl fàarí fárí [Ed.], fàrín [Db.], Aik fáai [Db.], pày [Ng.], Kib fa:l [Db.], fal [Ng.]. In [Edgar 1991b] Maba *ari and MslAik-Kib ${ }^{*}$ fali $\sim{ }^{*}$ falo are considered to be part of the same etymology; yet at the same time Edgar explicitly points out the irregularity of the loss of initial $f$ - in Maba, which cannot be reasonably explained or confirmed by any other examples. We should also point out that the second consonantal correspondence is irregular as well: Msl-Aik-Kib unequivocally points to an original lateral ${ }^{*}-l$-, which is normally preserved in Maba rather than shifted to $-r$ -

In the light of this evidence, it makes sense to strictly separate *fal-from *ari, facilitating the comparison between Mimi-N and Maba. However, which of the two stems is an innovation in the Swadesh meaning 'blood'? The Msl-Aik-Kib stem *fal-is better represented in the family from a distributional point of view; however, lack of successful internal etymologization for either of the two stems does not allow to exclude the possibility of Maba ari being an archaic retention ${ }^{4}$. The Mimi-N / Maba parallel can therefore count as a potential argument in

${ }^{4}$ Furthermore, it is hard to bypass the phonetic similarity between Maba ari and numerous East Central Sudanic forms for 'blood' that have the same shape (ari arI, sometimes $k=$ ari with prefixal $k=$ [Tucker 1940: 342-343]). 
favor of genetic relationship between the two or represent a borrowing (note that the direction would be unclear: simply assuming that Maba is always the donor and the two Mimis are always the recipients could turn out to be an anachronistic mistake).

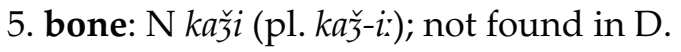

The $\mathrm{N}$ item is clearly comparable with the main Mab-Msl term for 'bone': Mab kànži-k

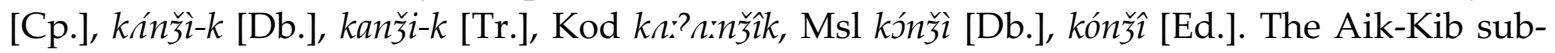
branch has a different set of forms (Aik žíngìr [Db.], žìngàr [Ng.], Kib žigidì [Db.], nžekedi [Ng.]) that can be etymologized together with Mab-Msl only under the assumption of a metathesis with subsequent vocalic assimilation $\left.\left({ }^{*} k\right\lrcorner n \check{z} i \rightarrow{ }^{*} n \check{z} \jmath k i \rightarrow{ }^{*}(n) \check{z} i g i\right)$, which would be rather shaky. Nevertheless, the Mab-Msl term is an acceptable candidate for Proto-Maba status, and the lack of a nasal consonant in Mimi-N kaži should not be seen as an obstacle for comparison (the cluster $-n \check{\zeta}$ - is not attested in any of Nachtigal's data, meaning that denasalization in this case could easily have been regular).

6. claw (nail): D fer; not found in N.

Forms with the meaning 'fingernail' in Maban show a wide variety of variants that go back to clearly composite stems *ningirmi, *kingirmi, *sangirmi. Regardless of the origins of this variation, none of the variants bear even a passing resemblance to $\mathrm{D}$ fer.

7. die: D dafaya (?); not found in $\mathrm{N}$.

The main word for 'die' in Maban is a stem that may be reconstructed either as * $y i$ * $i y$ (based on the majority of reflexations, e. g. Kod yî., Msl ry [Ed.], Aik $i$ [Db.], $i:$ [Ng.]) or, taking into consideration the occasional apparition of a labial element in the root (e.g. Mab iy $\sim$ wi [Db.], sy [Lu.]; Kib iy uy [Db.]), as * $y$ with subsequent vocalic assimilation. In any case, this verbal root has no parallels in Mimi.

The strange Mimi-D form dafaya is nearly identical with Kod $t=a f a y-a$ 'death', a nominal derivative from Maba àfày 'to be lost, go astray; (fig.) to die'. This would suggest, first of all, that the D form is really a noun (it certainly does not look like a simple verbal root), and, second, that it is most probably a recent borrowing from one of the Maba dialects (since Mimi-D clearly may not have a closer genetic affinity with Maba than Maba has with Masalit, Aiki and the other Maban languages, this particular agreement between the two on the matter of a morphologically and semantically complex derivation is much better explained through horizontal rather than vertical transmission).

8. dog: N nuk (pl. nuge-si:); not found in D.

A direct match with Mab nûk [Cp., Db.], nug, miug [Ed.], Kod nuk. Beyond this superficial comparison, however, there are significant problems. The most widely distributed etymon for 'dog' in Maban is met in two variants: (a) *iň̌- $\rightarrow$ Msl inžè, inži [Db.] and (b) *minn, pl. * miň̌̌- $\rightarrow$ Aik, Kib mín [Ng.], mın, pl. mın̋̌i [Db.]. Both are easily reconcilable under the plausible assumption that $m=$ in Aik-Kib is a fossilized possessive prefix of the 1st p., i. e. = 'my dog' (as in Msl $m=i r$ 'my brother', $m=o$ ò 'my sister'; Aik m=ir 'my brother', $m=u ́ k$ 'my sister', etc.); other than that, the stems match each other bit for bit, and the original root for 'dog' is revealed as ${ }^{*} i \eta-\left({ }^{*} i n-\zeta z i\right.$ is the result of palatalization $\leftarrow{ }^{*} i \eta-d i$, where the latter is a productive nominal suffix in some Maban languages and, quite likely, Proto-Maba as well).

Since Maba is not in direct contact with these languages, this may hint at an important old isogloss between Maba and Central Sudanic as a sub-unit within the hypothetical Nilo-Saharan. 


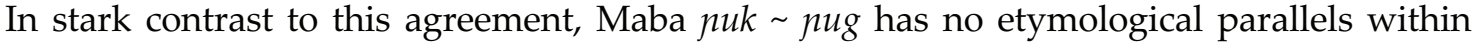
Maban, but is strikingly similar to the main word for 'dog' in some of the subbranches of Nilotic (cf. Proto-Teso-Lotuxo-Maa ${ }^{*}=k I=\eta \jmath k-$ [Vossen 1982: 354]; Proto-South Nilotic * $\eta o * k$ [Rottland 1982: 390]), as well as the isolated form $m u g$ 'dog' in Old Nubian and modern Nobiin which, in the light of its own distribution within Nubian, I have serious reason to suspect as the remainder of an old Nilotic substratum (Nubian languages do not have initial $\eta-$, making the transition $\eta$ - $\rightarrow m$ - before a labial vowel highly plausible; cf. also the curious phonetic variant miug in Edgar's Maba records). Such an odd pattern of dispersion would imply that the term is really a "Wanderwort" that may ultimately be of Nilotic origin (since this is the family in which it is most widely and unsuspiciously represented), and its common presence in Maba and Mimi-N is therefore not particularly diagnostic in the matter of determining their genetic connections.

\section{9. drink: D anక̌i; $\mathrm{N} a b$ (?).}

The D item is generally compatible with the main word for 'drink' in all Maban lan-

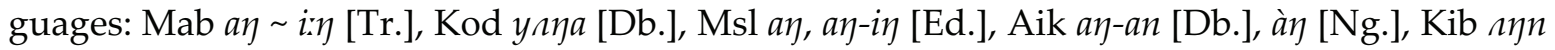

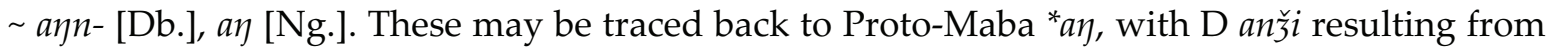
secondary palatalization ( ${ }^{*} a \eta-i \rightarrow{ }^{*} a n-i \rightarrow a n \check{z} i$; typologically similar scenarios sometimes work for Maban languages themselves, as well as their neighbours). One catch, however, is that in the data of Decorse, the D form anži is not just similar to, but completely identical with the form for Kodoi, which Decorse also records as anక̌i (cf. the non-palatalized version y^ya in P. Doornbos' Kodoi records). This is too much of a coincidence for us to be satisfied with suggesting identical non-trivial lines of development from *ay in Mimi-D and Kodoi, and, again, pushes in the direction of a contact explanation (or, worse still, a mistake in the data, with a Kodoi word accidentally having crept into the Mimi list).

In Mimi-N, the verbal root $a b$ 'drink' is not attested directly, but may be somewhat cautiously deduced from the comparison of two paradigmatic forms: ab-akat 'I do not drink' and $z=a b$-et 'drink!' ( $z=$ is a prefix, possibly with the meaning of the 2 nd p., frequently discovered in imperative forms recorded by Nachtigal: $z=a ́ i a$ 'come!', $z=i \eta$ 'go!', $z=u$ lko 'leave!' etc.). The root has no plausible equivalents in Maban.

10. dry: Not attested in either of the two Mimis.

\section{1. ear: D fer; N kuyi (pl. kury-i:).}

All of the forms for 'ear' in Maba are cognate: Mab kóyé [Cp.], k̇̀yé [Db.], ko-ik [Tr.], Kod kذ̀ye, Msl kwıyo [Ed.], kóyè [Db.], Aik kìsá [Db.], kàsá [Ng.], Kib knsa [Db.], kàsá [Ng.]. Edgar [1991b] considers this group of forms to contain an irregular reflexation of Proto-Maba *-s-, normally preserved in the intervocalic position. It seems, however, more plausible to reconstruct the basic stem as ${ }^{*} k y y$-, with a potentially regular development ${ }^{*}-y-\rightarrow^{*}-s$ - between two non-front vowels in the Kibet-Runga subbranch, for which there are no contradicting examples in the lexical corpus. The original paradigm may have been ${ }^{*} k \supset y-a$ or ${ }^{*} k \supset y-o$ (sg.) : ${ }^{*} k \supset y-\varepsilon$ (pl.), as preserved in Msl (kwıyo sg., kóyè pl. [Ed.]), with subsequent morphological restructuring of the paradigm in Maba.

The reconstruction ${ }^{*} k \supset y$-, obtained on purely internal grounds, agrees perfectly with Mimi-N kuyi (admittedly, this could also be a borrowing from Maba, but there are no additional arguments for this beyond phonetic similarity). Mimi-D fer ${ }^{5}$ is clearly a different root, with no clear parallels anywhere in Maban.

\footnotetext{
${ }^{5}$ It is not clear exactly what kind of articulation is denoted by the dot in Decorse's transcription (flap? retroflex?).
} 
12. eat: D jyam; not found in $\mathrm{N}$.

The Maba forms are: Mab an [Lu., Db., Tr.], Kod ná:, Msl in- ind- [Ed.], nó nán [Db.], Aik in-an [Db.], nj̀ nj̀-w [Ng.], Kib nó nà-wín [Db.], á=ná- [Ng.]. It is reasonable to assume that the palatal nasal $* n$ is the consonantal "foundation" that ties all of them together in a single etymology, but a more precise reconstruction is hard to arrive at without a detailed study of the historical morphophonology of all the languages concerned. At the very least, the MslAik-Kib isogloss suggests that the morphophonological variant ${ }^{*} n o$ should be projected onto the proto level.

The Mimi-D form nyam is similar to Maba, but any attempt at relating them genetically would have to face the problem of explaining what exactly happened to root-final $-m$ in ProtoMaba, a phoneme that is normally quite stable in this family. At the same time, the form *nam (or certain much more trivial variations on this shape) in the meaning 'eat' is found quite extensively in various Nilo-Saharan languages (Nilotic and Eastern Jebel families, among others), so there is no particular reason why this should be counted as a specific "Mimi-Maban" isogloss (if anything, Maba * $n$ s should primarily be compared with Proto-Central Sudanic * $n o$ 'to eat' [Ehret 2001: 343]).

13. egg: D ̌̌ulut; not found in $\mathrm{N}$.

No parallels for the Mimi-D word; the most general equivalent for 'egg' in Maban is a

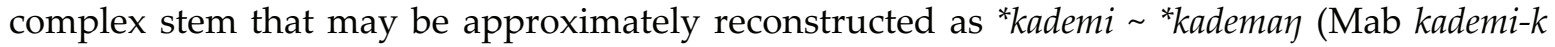
[Tr.], etc.).

It should be noted that the voiced palatal affricate $\breve{z}$ is not encountered in more than three or four words in Mimi-D, at least one of them a transparent recent borrowing (želid 'skin' $\leftarrow$ Arabic žild), which is in itself sufficient to doubt its archaicity. Additionally, it has an uncanny resemblance with certain terms for 'egg' met in Eastern Sudanic languages (cf., in particular, Gaam kolo-d 'egg', where $-d$ is a productive nominal suffix), again, suggesting possible areal ways of diffusion.

14. eye: D dyo (pl.); N kal (pl. kal-ai).

The basic root for 'eye' in Maban is highly stable, although final stem vowels differ depending on the language: Mab kàš̀̀-k [Lu.], kàsì-k [Cp., Db.], Kod kn:sî-k, Msl kó:-gí, kذ̀:-gí [Ed., Db.], Aik káso-ùk, kásò-ok [Db.], kàs̀̀-k [Ng.], Kib kàs [Ng.], ka.s [Db.]. The reconstruction is *kas-, with the Msl form reflecting an assimilated and contracted variant ( ${ }^{*} k a s o-g i \rightarrow{ }^{*} k o s-g i \rightarrow k o: g i$, cf. the morphologically simpler plural form kó:sî $\left.\leftarrow{ }^{*} k a s o-i\right)$.

It is seriously tempting to relate this * kas- to Mimi-N kal (as well as its attested derivative $k a l-i$ 'spring', reflecting a typical North African semantic association; note that all of the Maban items share the same polysemy), but such a comparison would run into the serious issue of the correspondence "Maban *-s- : Mimi-N -l-", unsubstantiated by further examples. Still, the comparandum is not entirely worthless, considering that Nachtigal's list does not contain even a single lexical item with intervocal $-s^{-}$, a fact that could, among other possibilities, reflect a process of lateralization $\left({ }^{*} s_{-} \rightarrow{ }^{*} \hat{S}^{-} \rightarrow-l-\right)$, rather atypical for "Nilo-Saharan" languages, but not unknown in the neighboring Chadic family.

The Mimi-D plural form $d y o$, on the other hand, is thoroughly uncomparable with Maban, nor does it find convincing parallels in any other parts of "Nilo-Saharan".

15. fire: D sou; not found in N.

There are two main groups of forms for 'fire' in Maban: (a) Maba-Masalit *was- $i \sim$ *was- $u$ (Mab wàsí-k [Lu.], Kod wasî-k, Msl wásì, wàasí [Db.], wáasú [Ed.]), most likely derived from the 
verbal root was- 'to burn', attested as such in H. Barth's recordings of Maba; (b) Kibet-Runga *nusu-k (Aik nùsò-k [Ng.], Kib nasa-k [Ng.], cf. also Daggal nusu-k, Mourro nusv-k id.).

To somehow relate Mimi-D sou to any of these two forms would require a series of unwarranted assumptions: it could be equally well related to *was- through some structural transformations (e. g. metathesis: ${ }^{*}$ sawu $\sim{ }^{*}$ wasu), or to ${ }^{*} n u s u$ if the latter were also to be analyzed as an old derived stem $\leftarrow{ }^{*} n(V)=s u$, where $n=$ is a productive causative prefix in Maban. On the other hand, one could just as well try to establish a connection with other phonetically similar words for 'fire' in the area - e. g. Central Sudanic (Kresh əšs 'fire'). Overall, this cannot be qualified as an exclusive and/or reliable Mimi-Maban isogloss.

16. foot: D rep ('pieds'), sem ('jambes'); N zay ('Bein').

Although the basic stems for 'foot' and 'leg' are not generally distinguished in the area, Decorses still gives two different equivalents, both of which we adduce here for security, even though not one of them finds any correlations in Maba.

In stark contrast, Mimi-N zay is easily comparable with the main word for 'foot' in Maba-

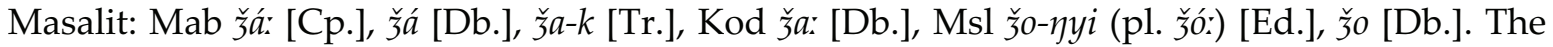
only thing that really needs to be "explained away" here is final $-\eta$, which fits in well with the

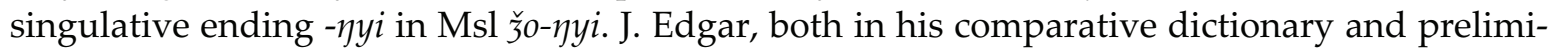
nary reconstruction of Proto-Maba, tries to relate Maba-Masalit *̌̌a or *žaw with Kibet-Runga *daw-di 'foot' (Aik dá(w)ìdí [Db.], dj̀í, dòdí [Ng.], Kib dnd-i [Db.], dòodí [Ng.]), but there is no real phonological basis on which to do this, since the correspondence "Maba-Masalit *̌ ${ }^{*}$ : Kibet-Runga *d-" does not exist. This means that $* \check{z} a(w)$ is a separate root, not the result of some recent palatalization in parts of Maban, which would rather imply genetic cognation with Mimi-N than recent borrowing (were this a recent borrowing, the initial consonant in Mimi-N would have probably been $\check{z}^{-}$).

17. hair: D suf; N fuil (pl. fu:l-i:).

Neither of the two entries matches with the basic Maban word for 'hair', provisionally reconstructed as *tofi on the basis of Mab tifí-k [Cp., Db.], tefe [Tr.], Kod tîfí-k [Db.], Msl tí:fa te:fa [Ed.], Aik (ki) tòw [Ng.], Kib towi [Db.], tow [Ng.]. Mimi-D is pointed out as a likely borrowing from Arabic șu:f 'wool, hair' already by Gaudefroy-Demombynes; Mimi-N fu:l simply has no etymology.

18. hand: D sil ('main'), mele ('bras'); $\mathrm{N}$ rai (pl. rai-da; 'Arm').

As in the case of 'foot / leg', Maban languages do not distinguish between 'hand' and 'arm': the basic equivalent for both is Mab kárá: [Cp., Lk.], kar-ak [Tr.], Kod knrrá, Msl kórj̀, kìrj̀ [Db., Ed.], Aik kàrá [Db., Ng.], Kib kárá [Db.], kàrá [Ng.]. Again, Mimi-N is closer to Maban typologically in that it also (probably) does not have the semantic distinction; however, this time the proper lexical equivalent (rai) is unrelatable. No parallels between Maban and Mimi-D, either.

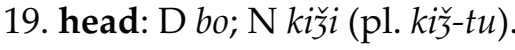

The main (and only) equivalent for 'head' in Maban is Mab kǐ̌- $i$ [Cp.], kiži [Db.], kǐ̌-ik [Tr.], Kod kǐ̌î̀, Msl kúžò, kí̧̌i [Db.], kí̌̌ô, kúžô [Ed.], Aik ki: [Db.], kì [Ng.], Kib kiče [Db.], kič [Ng.] $\leftarrow$ Proto-Maban ${ }^{*} k i \zeta ̌-$. This is a one-to-one match with Mimi-N; one cannot a priori exclude borrowing from a Maba dialect, but there is no unavoidable necessity to accept this scenario, considering the perfect "reconstructibility" of the item on the Proto-Maban level. On the other hand, it should also be noted that the Mimi-N word shows exactly the same morphological 
characteristics as Maba, cf. the attested plural form kiž-tu= Maba kǐ̌-tú: [Cp.]. This coincidence cannot represent a common retention, since the plural suffix - $t u$ for this stem is characteristic only of Maba proper, not of Masalit or Kibet-Runga (both of which form the plural of this verb through vowel gradation). Thus, either the entire paradigm has been borrowed into Mimi-N from Maba, or Mimi-N has preserved the original root, but modified its paradigm through a grammatical borrowing from Maba (Lukas \& Völckers [1939: 150-151] note several such loans of plural endings).

Mimi-D bo has no Maban parallels whatsoever (its closest comparandum, as noted already in [Ehret 2001], is to be found in Songhay boy 'head', most likely a chance resemblance). It is interesting to note the existence of the word kiži in Mimi-D, in the meaning 'old man' possibly 'elder', 'chief', borrowed from Maban in its figurative usage?

20. hear: Not attested in either of the two Mimis.

21. heart: Not attested in either of the two Mimis.

22. horn: D kamin; not found in N.

Attested forms for 'horn' in Maban are as follows: Mab kèmí-k [Cp.], kem-lik [Db.], kami-k [Tr.], Kod kemî-k, Msl kám-î [Ed.], kémmì, kìmì [Db.], Aik, Kib g^m-di [Db.], gàm-dí [Ng.]. There is a slight problem here concerning the initial consonant, but existing data allow to suggest a regular devoicing of Proto-Maban ${ }^{*} g$ - in Maba-Masalit (cf. another convincing example in Mab kamur, Msl kàmárì 'beard' = Aik gàm-sì id.; contradicting examples are almost non-existent, with the possible exception of Mab gùr, Msl gur-gi 'monkey' = Aik àgùr id., where it is likely that Maba-Masalit reflect a formerly intervocalic consonant rather than a formerly initial one).

The reconstruction * ${ }^{*} a m-i$ agrees well with Mimi-D kamin, provided $-n$ is a suffix and the difference in laryngeal features may be overlooked. Explaining the word away as a recent borrowing is not altogether easy due to morphological differences ( $-n$ as a suffix is not attested for this lexeme either in the singular or the plural forms anywhere in Maban).

23. I: Unfortunately, personal pronouns (a data subset that could have been of major assistance in settling our problem) have not been recorded at all for either of the two Mimis.

24. kill: D kuduma; not found in N.

This word has to be analyzed in conjunction with the adjectival form kudomo 'dead'. The exact same form, kuduma 'kill', is also noted by Gaudefroy-Demombynes for the little-known Maban dialect of Kashmere. However, the principal equivalent for 'kill' in all well-described Maban languages reflects an entirely different proto-stem, *uy: Mab uy [Ed.], wúy [Db.], iu [Tr.], Kod wuya, Msl iyaw iwi [Ed.], úi [Db.], Aik ús [Db.], òs sàw [Ng.], Kib us usın [Db.], asa [Ng.].

So, where does kuduma come from? It is probably the same word as Mab ùdùm 'to hit' [Lk.], with the plural object derived stem $k=\grave{u} d \grave{u m u ̀ ~ ' t o ~ h i t ~(m a n y) ' ~ t h a t ~ c o n t a i n s ~ t h e ~ r a r e ~ v e r b a l ~}$ prefix $k=$ described in [Lukas 1952: 98]. This would logically suggest that Kashmere kuduma 'kill' is a relatively recent (and, from the point of view of semantic typology, quite natural) innovation - and that, consequently, Mimi-D kuduma 'kill' is, in all likelihood, a borrowing from one of the Maba dialects, possibly from the very same one that also yielded tafaya 'die' (see above).

25. leaf: Not attested in either of the two Mimis. 
26. louse: Not attested in either of the two Mimis.

27. meat: D nyu; N ney (pl. ney-ni).

This is the first (and last!) time on the list that forms in the two Mimi languages actually resemble each other (although the segmental resemblance is basically restricted to the initial consonant).

The main word for 'meat' in Maban is also similar: Mab nú:nú [Lu.], nù-k [Cp.], Kod nu: [Db.], Msl nú-gì, núng-ú [Db., St.], nù-gí [Ed.] (Kibet-Runga has a non-comparable innovation). The forms may be traced back to two different variants: ${ }^{*} \eta u(:)$ and *nunu * $n u \eta u$, where the former is most likely the result of contraction from the latter (since there is no -nu suffix in Maban, and the probability of reduplication in this nominal stem is very low). Edgar further suggests a connection between this root and * $m 0$ 'to eat' (see above) - quite realistic from the view of areal semantic typology, but not entirely transparent as to the underlying derivational model.

Mimi-D nyu is clearly compatible with this etymon, although it could be either an etymological cognate or, once again, a recent borrowing from one of the Maba dialects. As for Mimi$\mathrm{N}$ ney, it should also be drafted into the comparison due to complete consonantal compatibility with the protovariant ${ }^{*} \eta u \eta u$; front vocalism could have been a result of palatalizing influence on the part of the initial consonant (and other scenarios are possible as well).

\section{8. moon: $\mathrm{D} a \dot{r} ;$ not found in $\mathrm{N}$.}

The original word for 'moon' in Maban is represented by the following reflexes: Mab

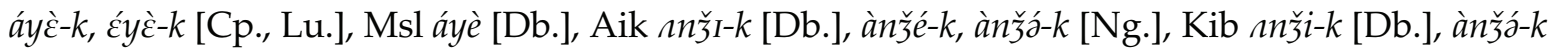
[Ng.]. Maba-Masalit ${ }^{*} a y \varepsilon$ and Kibet-Runga *anži are reconcilable with each other, but only through a somewhat complicated scenario that requires postulating an original structure *ani-E-(k), where *ani- may be an old verbal root with the meaning 'to shine' (same as in the word 'sun', see below), and $-\varepsilon$ - is the same nominal suffix that is also found in the parallel form menu- $\varepsilon-k$ 'star' in Maba. Juxtaposition of the original palatal nasal with two front vowels in a row leads to diphthongization and, eventually, affricativization in Kibet-Runga: *ani-E- $\rightarrow$ ${ }^{*}$ any $\varepsilon^{-} \rightarrow{ }^{*}$ anžc-.

Regardless of the details, neither the original root *ani-, nor its "permutated" forms in modern dialects do not agree well with Mimi-D $a \dot{r}$, which is significantly closer in shape to forms in various Saharan languages (Tubu auri, etc.) or those located much further east (South Nilotic, Omotic, etc.).

29. mouth: D nyo; N mil (pl. mil-u:).

In Maban, the word 'mouth' is one of the isoglosses that sharply distinguishes MabaMasalit from Kibet-Runga: the former has *kana (Mab káná [Cp., Tr.], kına [Db.], Kod kına, Msl kánà [Ed.]), the latter a monosyllabic *yu (Aik yù-k [Ng.], Kib yù [Db.], yù-k [Ng.]). Both items are heavily polysemous (for Maba-Masalit, additional meanings 'language', 'speech' are attested, for Kibet-Runga one has 'lip' and 'edge'), but no clear indications have been found so far as to which of them can be considered more archaic in the required Swadesh meaning.

Kibet-Runga * $y u$, from a purely speculative point of view, may be compared with Mimi-D nyo, but reasonable historical scenarios that could securely tie them together are missing: initial palatal $n$-is a fairly frequent segment in all Maban languages, including Kibet-Runga, and there are no factors, attested or hypothetical, that could lead to its being dropped in that branch. (The opposite development, i. e. nasalization ${ }^{*} y-\rightarrow{ }^{-}$- in Mimi-D, is typologically strange, and there is at least one example of an actual $y$ - in the initial position in that language: yakoe 'to see'). 
Mimi-N mil, however, is even less relatable to any of the listed Maban items. It probably makes sense to mention that the word perfectly coincides with the principal Maban word for 'name' ( ${ }^{*}$ mil-i $\sim$ *mel- $i \rightarrow$ Mab mílí-i [Cp., Db.], etc.), but the semantic transition from 'mouth' to 'name' is not really well known for the concerned linguistic area (or, in fact, for anywhere), so that any such etymologization, if used during the stage of ascertaining relationship, would be tenuous; in any case, even if true, it does not have the required lexicostatistical significance.

30. name: Not attested in either of the two Mimis.

31. new: Not attested in either of the two Mimis.

32. night: D lem; not found in $\mathrm{N}$.

Mimi-D has no parallels in Maban, where all attested forms are divided between reflexations of such proto-stems as *ise (Mab išè [Cp., Lu.], iše, a:ši:a [Tr.], Kod îše) or *dind- (Aik dì:ndé [Ng.], Kib dindo [Db.], díndò [Ng.]).

33. nose: D fir; $\mathrm{N}$ hur (pl. hur-u:).

Although $h$ - is occasionally encountered in the Sudanic area as a result of delabialization from $f$-, it is quite unlikely that the development $f$ - $\rightarrow h$ - ever took place in Mimi-N, considering the firm attestation of at least several $f$-initial items (cf. 'hair' above, as well as faila 'back', fula 'butter', etc.). Therefore, Mimi-D and Mimi-N cannot be grouped together.

For 'nose', Maban languages show two phonetically similar, but etymologically incompatible groups of forms: (a) Mab bón [Cp.], boin [Tr.], Kod bon $\leftarrow{ }^{*}$ bon (?); (b) Aik mùndú [Ng.], mòndú [Db.], Kib mùndù [Ng.], mundu [Db.] $\leftarrow{ }^{*} m u n d u$. (A third form is attested in Msl: dúrmí [Ed.], dúrmì [Db.] - but it is extremely similar to the corresponding item in nearby Fur, where it is morphologically complex: sg. $d=\grave{o r m i}$, pl. $k=\grave{o r m i}$, and is most likely a borrowing from therein). Neither of these roots is comparable with any of the two Mimi items.

34. not: Not attested in either of the two Mimis. The equivalent for French non 'no' in Mimi-D is written down as lala and, quite justly, marked as an Arabic loan.

35. one: D deg; N ulun.

The majority of Maban languages seemingly form the basic numeral ' 1 ' from the same stem, but with various suffixal extensions, cf.: Mab tó: [Lu.], tek [Tr.], tar tẹ [Ed.], tغ̀:n ték tó: [Cp.], Kod tek, Msl tó: tò:m tyǒm [Ed.], tòu tióu [St.], Aik tùwá [Db.], Kib tuwni [Db.]. Although not all of these complex stems are equally transparent, it makes better sense to "lump" them together than postulate a wide variety of different roots with the same meaning. The most common vocalization of the stem is labial ${ }^{*} O{ }^{*} u$, which is changed to a front vowel only in several dialectal varieties of Maba; the only possible way in which this could have happened would be contraction with a suffix, e. g. ${ }^{*} t o-e(-) k \rightarrow t e k$.

In the light of this, it is quite telling that Mimi-D deg shows a close connection not so much with Common Maban *to- as it does with the specifically Maba variant tek; this is a strong argument in favor of the borrowed, rather than inherited, nature of deg.

Mimi-N ulun, segmentable into ul-un (cf. zalk-un 'three', alg-un 'eight'), has no straightforward parallels in Maban. If the first vowel is the result of an older assimilation, one could think of a possible Central Sudanic connection (cf. Moru-Madi ${ }^{*} a l o ~ ~ * a l v$, etc.).

36. rain: Apparently, the same word as 'water' in both Mimis, see below. 
37. smoke: D dohan; not found in N. The Mimi-D word is a transparent borrowing from Arabic.

38. star: Not attested in either of the two Mimis.

39. stone: D muguru; not attested in N.

The word muguru has no parallels in Maban whatsoever and does not, in fact, look very "Maban" at all. Much more interesting is the word for 'mountain' ('mountain' and 'stone' is a very frequent polysemy in the area), $k u d u$, which is a perfect match for Maba kódó-k [Db.] 'stone, mountain'; once again, however, this may be explained as either common heritage or borrowing, and further analysis is necessary to tilt the scale towards as particular choice. This is where the situation gets tricky.

The attested Maba forms are listed by Edgar as kódó-k [Db.], kòsdró [Lu.], kodro-k koro-k [Ed.], Kod $k\lrcorner d \jmath-k$. This diversity reflects two stems, one simple ( $\left.{ }^{*} k \jmath d \jmath\right)$ and one extended with a diminutive suffix $\left({ }^{*} k \supset d \jmath-r o\right.$, with subsequent reduction of the second syllable and occasional cluster simplification). So far so good; however, already Msl has instead the form kondola [Ed.], and in Aik we see kòmà:-ndí [Ng.]. Is this a case of three different etyma, or one single stem reshaped through morphological processes?

The Aik form actually speaks in favor of the second answer. It is clearly cognate with Msl kómà kúmà [Ed.] 'mountain', and a reduced variant of it is also evident in Murro $k^{h} v m d e$ 'mountain'. The complex stem *kom $(V)-n d V$ - also yields Msl kondola $\left(\leftarrow{ }^{*} k o m-n d V\right.$-la) and, quite possibly, Maba kodo $\leftarrow{ }^{*} k o m-n d o$.

This internal etymology of kodo is not altogether secure, but, regardless of its reliability, we once again have a case of a direct match between Mimi-D and Maba proper rather than Mimi-D and Maban as a family. If Maba $k \jmath d \jmath \leftarrow{ }^{*} k o m-n d o$ as suggested, Mimi-D $k u d u$ is a transparent borrowing. If it is a distinct root, chances of cognation are only slightly higher, since Maba kodo is not reconstructible on a higher level.

40. sun: D sey; not attested in $\mathrm{N}$.

The basic word 'sun' in Maban is expressed with the stem *ani- (possibly the same as in

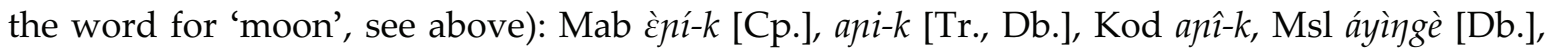
áingè [St.], Aik ànín [Ng., Db.], Kib ànín [Ng.], ánìy [Db.]. None of the attested forms resemble Mimi-D sey in any way.

41. tail: D danap; not attested in N. The D word is a transparent Arabic loan $(\leftarrow$ danab).

42. thou: Not attested in either of the two Mimis (see 'I').

43. tongue: Not attested in either of the two Mimis. For some reason, Edgar quotes the Mimi-N word twice: once as 'mouth' [Edgar 1991a: 314] and once as 'tongue' [Edgar 1991a: 237], even though in [Lukas \& Völckers 1939] only the German meaning 'Mund' is listed; I am not aware whether Edgar had access to Nachtigal's original manuscript and if yes, whether both meanings were indeed present there or if this is simply an accidental slip-up.

Even if Mimi-N mil 'tongue' is not an invention, it is barely comparable with Maban forms for 'tongue' under the assumption of a metathesis (!) from *lim: cf. Mab dilmí-k [Cp.], Kod dilmî- $k$, Msl gèlmédì [Ed.], gélmàndì [Db.], gélmàndì [St.], Aik àdì(y)ím [Ng.], ádìyím [Db.], Kib àdàlám [Ng.], adilcm [Db.], all derived from a complex proto-stem ${ }^{*}(a=) \operatorname{dil}(\partial) m(-i)$. It goes without saying that such a comparison would be inadmissible as a significant argument for relationship. 
44. tooth: D nain (pl.); N zi:k-a (pl. zi:k-u).

The plural form in Mimi-D cannot be related to any semantically close Maban equivalents; its phonetically closest equivalents, as already pointed out by Gaudefroy-Demombynes, are to be found in Central Sudanic (cf. Bagiro $\eta \bar{a} \eta \bar{a}$ and other corresponding forms in related languages of the Sara-Bongo-Bagirmi group).

As for the stem $z i: k$ - in Mimi-N, it does bear a marginal resemblance to the most common word for 'tooth' in Maban: cf. Mab sàtí-k [Cp., Db.], Kod satí-k, Aik sàdí [Ng.], sìdì [Db.], Kib sàd-í [Ng., Db.] $\leftarrow$ Proto-Maban *saT-i (exact quality of the intervocalic consonant is difficult to establish with precision). However, the resemblance is essentially limited to the initial consonant and would require a difficult "accommodating" scenario, e. g. one that assumes a particularly archaic nature for the singulative form *sadi-k, with subsequent lenition and dropping of ${ }^{*}-d$ - and fossilization of $-k:{ }^{*}$ sadi- $k \rightarrow{ }^{*} z a d i-k \rightarrow{ }^{*} z a i-k \rightarrow{ }^{*} z i: k$. No data are available to support such a complex hypothesis.

45. tree: $\mathrm{D} s u$; not found in $\mathrm{N}$.

The D item is comparable to the main word for 'tree' in Maba-Masalit: Mab sùng-j̀k [Cp.], sungo-ok [Db.], Kod sūgo-ok, Msl sínyí síngí síngé [Ed.], síng-è [Db.] (Kibet-Runga has an oddly shaped stem - since word-initial $r$ - is very rare in these languages $-{ }^{*} r i$ instead). The original vocalism is hard to determine, since the vowel seems to undergo assimilation with the suffixal vocalism in both languages, reflecting complex stems *suy-o and *siy- $i$ respectively in Maba and Masalit.

If the variant * suy-o is the one that is more archaic here, its first syllable is an exact match with Mimi-D su. However, there is still a major problem concerning the velar nasal. Intervocalic $-\eta$ - is a fairly frequent presence in this language (cf. 'water' below and numerous other examples in Decorse's list); word-final $-\eta$ is not, so one could theoretically imagine the regularity of the transition ${ }^{*}$ su $\rightarrow s u$, but additional data would be necessary to confirm it (it should also be noted that typologically, at least, dropping of word-final nasals without a trace is hardly typical of any languages in the "Nilo-Saharan" area, and, as far as we know, Decorse did not indicate the presence of nasalized vowels in his Mimi).

\section{6. two: D mel; $\mathrm{N}$ sön.}

All of the words for 'two' in Maban are cognate: Mab mbà:r mbír [Lu.], mbà:r [Cp.], Kod mba:r, Msl mbárrà mbìrà [Db.], mbará: [St.], Aik mbà [Ng.], mbá [Db.], Kib mbar [Ng.], mba:r [Db.]. Loss of final $-r$ in Aik is irregular, but we find this consonant reinstated in such deriva-

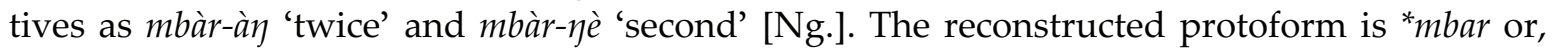
rather, *mba:r with phonologically relevant vowel length.

The form is highly unusual in that it is the only securely reconstructed Proto-Maban item with initial prenasalized ${ }^{*} m b$-, which invites various attempts at speculative internal reconstruction (contraction from a former ${ }^{*} m V$-ba-ar; prefixation $\left({ }^{*} m=b a r\right)$; even borrowing from a Niger-Congo source where phonetically similar forms are occasionally encountered). A particularly promising scenario is that ${ }^{*} m b a: r$ is the result of contraction of a formerly compound stem: * $m b V$-ar, where * $m b V$ is an adverbial/prepositional lexeme, attested per se in Msl bo mbo 'together (with)' [Ed.], Aik mba 'with; and' [Ng.] (presence of an old initial cluster, possibly itself the result of contraction, in such a semi-clitical auxiliary morpheme is more understandable than in the word for 'two'), and *-ar is really the old root for 'two', with multiple further external correlates in potentially related "Nilo-Saharan" languages.

The reconstructed *mba:r bears an obvious resemblance to Mimi-D mel. There is, however, an insurmountable problem in that there is no evidence whatsoever for the transition ${ }^{*}-r \rightarrow-l$ 
in that language; in fact, word-final $-r$ (or $-\dot{r}$, as it is sometimes marked) is found all over the place along with word-final $-l$, so that, without further arguments, we cannot make the transition from "phonetic resemblance" to "phonetic correspondence". In fact, if anything, it is the Mimi-D word for '4', mir, that should be compared to Maban mba:r (and even then, there still remain some issues with the vocalism).

In comparison, Mimi-N sön is clearly no match for *mba:r. It is, however, interesting, following J. Edgar's suggestion, to compare it with the Msl words for 'twin': sèn-írù sèn-áká [Ed.] (not clear how they relate to Mab sumbur [Lk.] pl. 'twins'). Theoretically, both go back to a common root *sen- meaning 'both' or 'pair', employed in Proto-Maban along with the regular *mba:r 'two'. Clearly, this is not a reliable etymology, but it is at least preferable to viewing Mimi-N as, say, a Semitism ( $\leftarrow^{*} \underline{t} n y$ ' 2 '; no other Semitisms or Arabisms are attested in Mimi-N numerals).

47. water: D engi; N sun. Both words are polysemous in the meanings 'water' and 'rain'.

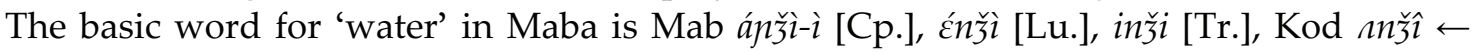
*anక̌i with various vocalic assimilations. However, in terms of general distribution of cognates the more widespread equivalent for this Swadesh item is Msl sà: = Aik tà- $k$ [Ng.], Kib ta [Ng.], ta: [Db.]. The correspondence "Masalit $s$ : Kibet-Runga * $t$ " is perfectly regular and has been recorded already by J. Edgar, although it coexists along with the more "usual" correspondences $s: s, t: t$, and its precise phonetic nature in Proto-Maban is unclear. We mark the underlying phoneme as ${ }^{*} s_{1}$ and, accordingly, reconstruct the word for 'water' as ${ }^{*} s_{1} a$ :. Regardless of whether Maba-Masalit is to be regarded as one of the two primary branches of Maban or if we postulate an original tripartite split of the family, ${ }^{*} s_{1} a$ : makes more sense as the primary ProtoMaban item for 'water' than Maba *anži.

Mimi-D engi has been compared with Maba *anక̌i already by Gaudefroy-Demombynes. This would imply that *an̋̌i is a phonetically innovative form - a result of palatalization from earlier *angi, even though supporting evidence for such a palatalization in Maba history is lacking. What is even worse is that, once again, the attested isogloss is between Mimi-D and Maba, as opposed to Mimi-D and Maban in general: even if the resemblance between engi and *anگ̌ $i$ is not coincidental, it cannot be used as a solid argument for the "Maban" nature of Mimi-D. (We should also add that phonetically similar words for 'water / rain' are amply attested throughout the area - cf. Kanuri $n \zeta \hat{\jmath}_{\imath}$ 'water', Deme /Sara-Bongo-Bagirmi group of Central Sudanic/ $n \check{z} \bar{\imath}$ 'rain', etc. - and that, before making any definitive statements on Mimi-D engi, one should first complete a detailed study of the possible relations of all such items in the more thoroughly described "Nilo-Saharan" languages).

The Mimi-N form sun is unique in that it is the only case where a given word in either of the two Mimis constitutes a perfect match with Jungraithmayr's “third Mimi”, i. e. Amdang / Biltine: súnù [Jg.] = sunu sunu [Wolf] 'water'. This Amdang word is most likely cognate with Fur su:n 'waterhole, well', although the direction of the semantic development cannot be established with certainty. Regardless of that, there is no question whatsoever about Mimi-N sharing a close genetic relationship with Fur-Amdang, meaning that Mimi-N sun should rather be considered a borrowing from one of the members of this small family (the opposite possibility is also not completely excluded).

48. we: Not attested in either of the two Mimis (see 'I').

49-50. what, who: D neta 'what?'; not found in N.

The only known interrogative in Mimi-D is comparable with the system of interrogatives in Maban, especially the inanimate * $\eta \varepsilon$ 'what?' (with a palatalized variant * $n \varepsilon$ in some of the 


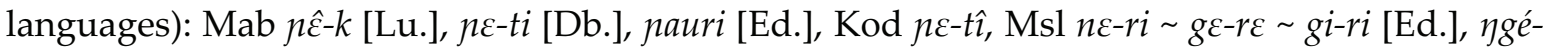

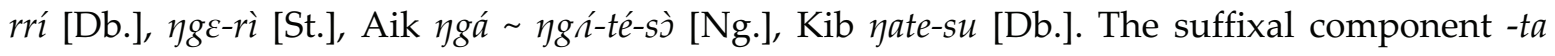
(traces of an emphatic particle?) may be the same as -ti- / -te- in some of the attested Maban forms. Of course, many other "Nilo-Saharan" (and other African) languages have $\eta$ - $/ \eta$-initial interrogatives as well.

\section{Basic statistics}

It is now possible to summarize the findings described above from an elementary quantitative point of view. Two parameters, the values for which are not altogether difficult to establish objectively, will be of primary importance:

(a) Phonetic compatibility (indicated as PC in the table below). All of the comparisons of Mimi words with their possible correlates in Maban are based on resemblance rather than on regular correspondences: the latter are impossible to establish due to scarceness of known data multiplied by an apparently significant time depth of the hypothetical relationship. Nevertheless, there are resemblances and resemblances: we may distinguish between "easily compatible" cases, in which the resemblance is either complete (i. e. the segments match bit-by-bit) or partial, with typologically credible and uncontroversial scenarios presented to explain the differences", and "dubiously compatible" ones, which run into significant problems that have no easy explanation (e. g. the resemblance between Maban “mba:r 'two' and Mimi-D mel id.);

(b) Distribution of potential cognates (indicated as DC in the table below). Two words that belong to two languages belonging to different families are much more likely to have been inherited from a common ancestor if it can be shown that both are reconstructible in their respective families, i. e. can be projected onto the proto-level without any serious controversies. (In lexicostatistics, this implies not just a bare projection of the phonetic shape of the word, but its "reconstructibility" as the pair "shape : meaning". This is very important to keep in mind, because it means that, e. g., the resemblance between Mimi-N sön 'two' and Msl sèn-írù 'twin' cannot be used as an argument in our test: even if the Msl item is reconstructible per se for Proto-Maban, it is certainly not reconstructible in the required meaning 'two'.)

In the current situation, this essentially means discriminating between situations in which the Maban parallel is limited only to the Maba (Maba-Kodoi) dialect cluster, and situations in which it is attested across different branches of Maban. More precisely, the "disturbing" (indicative of contact rather than relationship) situation occurs when the Mimi word has a parallel in Maba, but the other three languages (Masalit, Aiki, and Kibet) agree on a different cognate for the corresponding Swadesh item. Another type of "disturbing" situation is when the Mimi word is comparable to a "pan-Maban" root, but is attested in a phonetic shape specifically close to the one in Maba (cf. 'drink' in Mimi-D).

Let us now arrange the results in the form of a table, which will, for every attested Mimi-D / Mimi-N word on the 50-item list, indicate easiness (+) or dubiousness (-) of phonetic compatibility, as well as two degrees of probability that the compared parallel is reconstructible for ProtoMaban: high (+) and low (-) (high = cognate found across several branches; or, cognate found only in Maba but Masalit and Kibet-Runga all show different cognates, "allowing" the Maba item to be projected onto Proto-Maban in the required meaning; low = "disturbing" situations described

${ }^{6}$ From a certain point of view, explainable "partial" resemblance is even better than "total resemblance" for a hypothesis of genetic relationship, since the latter, considering the unquestionable chronological distance between Mimi and Maban, will frequently lead to suspicions of borrowing. 
above). For further security, the Swadesh items themselves will be arranged in the order of "decreasing stability", based on the "stability index" introduced by Sergei Starostin in [Starostin 2004].

\begin{tabular}{|c|c|c|c|c|c|c|}
\hline Swadesh item & Mimi-D & PC & $\mathrm{DC}$ & Mimi-N & PC & $\overline{\mathrm{DC}}$ \\
\hline two & mel & - & + & sön & \multicolumn{2}{|c|}{$x$} \\
\hline eye & $d y o$ & \multicolumn{2}{|c|}{$x$} & kal & - & + \\
\hline fire & sou & - & + & - & & \\
\hline stone & muguru & \multicolumn{2}{|c|}{$x$} & & & \\
\hline hand & sil & \multicolumn{2}{|c|}{$x$} & rai & \multicolumn{2}{|c|}{$x$} \\
\hline what & neta & + & + & - & & \\
\hline die & dafaya & + & - & - & & \\
\hline drink & anక̌ $i$ & + & - & $a b$ & \multicolumn{2}{|c|}{$x$} \\
\hline dog & - & & & nuk & + & - \\
\hline moon & $a \dot{r}$ & \multicolumn{2}{|c|}{$x$} & - & & \\
\hline claw (nail) & fer & \multicolumn{2}{|c|}{$x$} & - & & \\
\hline blood & - & & & ari & + & - \\
\hline one & deg & + & - & $u l-u n$ & \multicolumn{2}{|c|}{$x$} \\
\hline tooth & nain & \multicolumn{2}{|c|}{$x$} & $z i: k$ & - & + \\
\hline eat & nyam & - & + & - & & \\
\hline tail & danap (Ar.) & \multicolumn{2}{|c|}{$x$} & & & \\
\hline hair & suf(Ar.?) & \multicolumn{2}{|c|}{$x$} & fu:l & \multicolumn{2}{|c|}{$x$} \\
\hline water & engi & - & - & sun (Fur?) & & \\
\hline nose & fir & \multicolumn{2}{|c|}{$x$} & hur & \multicolumn{2}{|c|}{$x$} \\
\hline mouth & nyo & - & + & mil & & \\
\hline ear & $f e \dot{r}$ & \multicolumn{2}{|c|}{$x$} & kuyi & + & + \\
\hline bird & - & & & kabal-a & + & - \\
\hline bone & - & & & $k a \check{z}-i$ & + & + \\
\hline sun & sey & \multicolumn{2}{|c|}{$x$} & - & & \\
\hline smoke & dohan (Ar.) & \multicolumn{2}{|c|}{$\times$} & & & \\
\hline tree & su & - & + & - & & \\
\hline kill & kuduma & + & - & - & & \\
\hline foot & rep & \multicolumn{2}{|c|}{$x$} & $z a \eta$ & + & + \\
\hline horn & kamin & + & + & - & & \\
\hline meat & nyu & + & + & ney & + & + \\
\hline egg & 亏̌ulut & \multicolumn{2}{|c|}{$x$} & - & & \\
\hline black & liwuk & + & + & - & & \\
\hline head & $b o$ & \multicolumn{2}{|c|}{$x$} & $k i \check{z}-i$ & + & + \\
\hline night & lem & \multicolumn{2}{|c|}{$x$} & - & & \\
\hline
\end{tabular}


Altogether:

Out of 30 of the attested Mimi-D items, 14 (46\%) have Maban comparanda, out of which 4 have significant distributional problems, $\mathbf{5}$ have serious issues with phonetic compatibility, $\mathbf{1}$ has both, and only 4 ('what', 'horn', 'meat', 'black') can count as “first-order" evidence. Of these 4, only 1 ('horn') is an exclusive Mimi-D/Maban isogloss, not attested in this meaning in any neighbouring languages.

Out of 18 of the attested Mimi-N items, 10 (55\%) have Maban comparanda, out of which 3 have significant distributional problems, $\mathbf{2}$ have serious issues with phonetic compatibility, $\mathbf{0}$ have both, and only 5 ('ear', 'bone', 'foot', 'meat', 'head') can count as "first-order" evidence. Of these 5, at least 3 ('ear', 'foot', 'head') are more or less exclusive Mimi-N/Maban isoglosses.

Out of 14 basic items on the list, for which equivalents are known in both Mimis, only 1 ('meat') is represented by entries that are phonetically similar to each other. The rest are completely incompatible.

\section{Conclusions}

The evidence presented here cannot, by any means, be qualified as "decisive" in providing us with a concise answer on the exact position of the two Mimis relative to Maban. Nevertheless, the following assertive statements can be made:

1. Mimi-D and Mimi-N are either not related between themselves, or related on such a deep level that conventional lexicostatistics is unable to uncover the relationship. This implies that, at best, only one of the two Mimis could form part of Maban, certainly not both at once.

2. Percentage-wise, evidence for Mimi-N's genetic relationship to Maba is stronger than for Mimi-D, with $27 \%$ (5 out of 18 ) of the words easily relatable to Proto-Maban as compared to Mimi-D's 13\% (4 out of 30), and a much larger share of exclusive MimiN/Maban than Mimi-D/Maban isoglosses.

3. There can be no doubt that both Mimis, in relatively recent times, have been in close areal contact with one or more dialects of the Maba (not Maban!) cluster, and that J. Greenberg's unconditional grouping of both with Maban was heavily influenced by some of these contact isoglosses, since he was unable to separate them from the more ambiguous pieces of data due to lack of sufficient information on Maban.

4. Even if one of the Mimis is more closely related to Maban than to any other potential constituent of "Nilo-Saharan", it makes little sense to speak of this Mimi as a "Maban" language; at best, it would be "para-Maban", separated from Proto-Maban (the ancestor of Maba-Masalit and Kibet-Runga) by such a huge time period that it would be better to speak of a "Mimi-Maban" taxon, of a higher order than simply Maban (e. g. "MimiMaban family", splitting into Mimi and Maban groups, etc.).

One very serious argument against "Mimi-Maban" is the observation that both Mimis show at least several unmistakable isoglosses with Maba or Maba-Masalit, yet there is not even a single credible isogloss between any of the Mimis and Kibet-Runga, the second branch of Maban that should, within the tree structure, be equidistant from Mimi. Research on ProtoMaban shows that there is no evidence to consider Kibet-Runga languages to have been particularly innovative compared to Maba-Masalit, meaning that their basic lexicon should pre- 
serve its share of archaisms, with further parallels to be found in Mimi. Lack of such parallels would seem to tilt the scale towards a general "contact" solution for both Mimis.

Nevertheless, it is recommendable to adopt the following as a current working model:

I. Mimi-D (Decorse's Mimi) is a language isolate. Its resemblances with Mimi can be explained as a mix of borrowings (including such transparent cases as dafaya, kuduma, etc.), a bit of common inheritance from a much older period ("Nilo-Saharan"), and several chance similarities that, sometimes, do not go beyond a single-consonant match. Actually, considering some external parallels mentioned above, it could make more sense to seek a connection between Mimi-D and the huge Central Sudanic family.

II. Mimi-N (Nachtigal's Mimi) may be related to Maban within the confines of a larger "Mimi-Maban" taxon. Its "lexical debt" to Maba is also on record (e. g., the word for 'dog'), but it is proportionally smaller than the one in Mimi-D. Suspicious things such as a lack of exclusive isoglosses with Kibet-Runga or the fact that most of the matches are confined to body parts (some of them sharing the same morphological features with Maba) may, after all, be simply due to the extremely limited scope of Nachtigal's list: it is not only shorter than Decorse's, but it is also very low on any parts of speech other than nouns.

Let us now test how well such a working model would hold on the remaining "less stable" 100-wordlist items on the Swadesh list. For brevity's sake, I will only list those Mimi-D and Mimi-N items that have reliable Maban comparanda, and keep the accompanying discussion to a minimum.

\section{A. In Mimi-D:}

belly: bok buk - cf. Mab tàbú-k [Lk., Cp.], tábù-k [Db.], Kod ta:bu:-k id. The comparison is mentioned already by Gaudefroy-Demombynes, and all the forms are grouped together in J. Edgar's dictionary under one entry. The comparison, however, would only be acceptable if it could be argued that $t a=$ in Maba-Kodoi is a fossilized prefix; until more cases of a formerly prefixal $t a=$ in this language have been discovered, we will have to settle for chance resemblance.

dry: negiri - cf. Mab nožir [Tr.], nǰží [Db.], Kod no:žîr [Db.] id. The resemblance does not seem accidental, but the Maba-Kodoi forms are actually complex nominal stems, derived, with the aid of the productive prefix $n=$, from a much shorter verbal root that is still preserved in Mab wò̌ [Lk.], ož [Tr.] 'to dry'. Prefixation of $n=$ is a common phenomenon in Maban and should be projected onto the proto-language state, but common Proto-Maban derived stems sharing the same prefix and suffix are so rarely met that it would be very hard to believe that negiri and nožir are both reflections of a common heritage ${ }^{7}$.

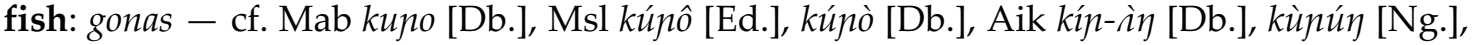

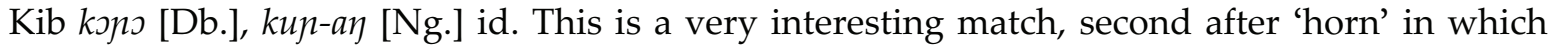
Mimi-D can be compared with an item securely reconstructible for Proto-Maban (as *kun-), provided $-(a)_{s}$ is a proper suffix in Mimi-D; due to phonetic differences, it is even harder to explain this word as a recent borrowing from Maba than to do the same for 'horn'.

full: pin - cf. Mab fin [Lk.], fing [Tr.], fin-ti [Db.], Kod fin-tı [Db.], Msl binga [Ed.] id. A Maba-Masalit isogloss; further relations with Aik bíč [Ng.], bíž-àsé [Db.], Kib bıč [Ng.] are un-

${ }^{7}$ It should be noted that, if Mimi-D negiri is a borrowing from Maba, this would surmise velarization of the palatal affricate in the borrowed item, even though there are transparent examples in Mimi-D that testify to the preservation of the original articulation (see 'head' on the sources of Mimi-D kiž i 'elder', etc.). Could this indicate at least two chronological strata of borrowings, or does that imply that the resemblance is, after all, coincidental? 
clear. A scenario under which the respective Mimi-D word could be genetically related to Maban is theoretically possible, but note, once again, that phonetically the Mimi-D word is closer to Maba than any other Maban language.

give: endi - cf. Mab and [Db.], Kod nndî id. The verb 'to give' is much more frequently encountered in Maban with a palatal nasal or palatal nasal cluster, cf. Mab jn [Lk.], onio [Tr.],

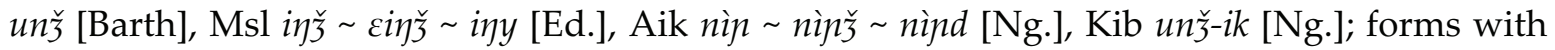
$-d-$, although probably also formed from the same root, have poor distribution and are probably innovative. Nevertheless, we could consider the Mimi-D parallel as one of the "dubiously compatible" cases.

good: kile - cf. Msl kàllá id. [Db.], but Mab kere-k [Ed.] id. (the correspondence "Msl -l- : Mab - $r$-" does not exist, so the words must belong to different etyma; ${ }^{*} K V l V$ is a widespread areal shape for 'good').

red: kukeya - cf. Mab kùkúyà-k [Lk., Cp., Db.], kukui-ok [Tr.], Kod kukuynk id. The words are clearly connected, but the Maba-Kodoi item is further related to Kib kò:nžík [Db.], kwònžé-k [Ng.] id. (same consonantal correspondence as in 'moon', see above), whereas the Mimi-D word specifically replicates the Maba shape of the word, characterized by reduplication, typical of color names in that language, but not in any other Maban languages. Thus, borrowing from Maba is the most natural solution.

road: lanak (cf. also se-lina mamai akae “où va cette route?”) - cf. Mab lina [Db.], lìnàk [Cp., Ed.], Kod lina 'road'. The word is exclusively Maba-Kodoi; an unmistakable borrowing.

see: yakoe - cf. Mab oko [Tr.], ókś yókó [Lk.], Kod yok id. Again, the etymon is not found outside of Maba-Kodoi, although this time around, it is potentially reconstructible for ProtoMaban (both Masalit and Kibet-Runga feature entirely different stems), so that a common ancestor for Maba *(y)sks and Mimi-D yakoe is not out of the question. Gaudefroy-Demombynes, however, is correct in pointing out additional parallels in nearby Central Sudanic languages (cf. Kresh óks; Bagiro àkj, etc.) that make this Mimi-Maba isogloss non-exclusive.

\section{B. In Mimi-N:}

belly: ti:k-a, pl. ti:k-u: - in Edgar's dictionary, this is lumped together with Mimi-D bok and Maban tàbú-k, etc., see above. The underlying idea is that this could somehow stem from an original ${ }^{*} t i b u-k(?)$, with lenition and deletion of the intervocalic labial and fossilization of the singulative suffix $-k$, but this is, of course, no less forcedly speculative than the possible connection between bok and tàbúk.

breast (more precisely - 'bosom', 'udder'): akun, pl. akun-i: - cf. Mab àngûn [Lk.], àngûn

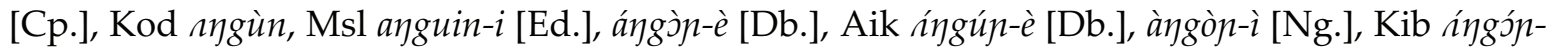

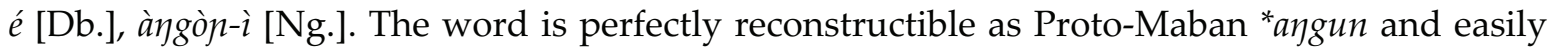
compatible with Mimi-N, although it should be noted that, once again, the Mimi-N paradigm is closest in shape to Maba (cf. in [Cp.]: àngûn, pl. àngún-í:).

knee: tumo, pl. tum-su: - cf. Mab tumo-k [Tr.], túmó: [Lk.], tumò [Db.], Kod tu:mo, Aik dımdi, pl. dumdu [Db.], dàmdí, pl. dámdú [Ng.], Kib dımti, pl. dımtu [Db.], dàmtí [Ng.]. The word is reconstructible for Proto-Maban as *dam- with various suffixes (root vocalism is not certain), but the Mimi-N word is again closest in form to Maba proper (although this time, the paradigm looks different: plural form in the Maba-Kodoi cluster is Mab tumò-žé [Db.], Kod tu:mo-ร̌z:).

The results of this further survey are, if not entirely predictable, at least unsurprising. For Mimi-D, there are only two more cases that could be added to the "genetic relationship" side of the argument, one of them being 'fish' (a word that very easily gets borrowed in between 
African languages, although in this particular case, the borrowing scenario is not straightforward), the other being 'see' (a non-exclusive isogloss) ${ }^{8}$; of the remaining items, at least three are almost certain borrowings ('dry', 'red', 'road'). As for Mimi-N, it simply yields two more (not counting 'belly') body parts that could be, with almost equal probability, ascribed to contact or relationship (since both are reconstructible for Proto-Maban).

The fact that, out of the remaining 50 items, we have been able to uncover comparanda for nine Mimi-D items compared to Mimi-N's three is easily explainable. First, Decorse's list is simply larger, per se, than Nachtigal's (cf. 30 vs. 18 attested items in the first half). Second, this may be taken as indicative of the fact that Decorse's Mimi had simply been in closer contact with Maba than Nachtigal's, which is why the number of discovered Maban $\rightarrow$ Mimi-D borrowings grows larger as we "move down" along the stability scale of the lexicostatistical lists.

Overall, further study of Mimi-D's resemblances with Maban only reaffirms the conclusion that the genetic link between these taxa was mistakenly established by Greenberg due to lack of sufficient data on the Maban family. (Ironically, it is exactly the principle of "mass comparison", advocated by Greenberg - although applied in a somewhat more strictly cladistic manner - that helps uncover the mistake). In reality, Mimi-D probably is (was) the sole survivor of a much more ancient stock, and the question of its external connections should only be reopened once we have gained a better understanding of the mutual relations of at least several major groups within Greenberg's "Nilo-Saharan" (e. g., the connections between Maban, Central Sudanic, Saharan, and Fur-Amdang).

Concerning Mimi-N, there seem to be enough words on the list for us to argue about a real exclusive genetic connection with Maban (rather than simply areal connection with Maba). A certain amount of doubt still remains, given that (a) all of these words are body parts (but Nachtigal's list is indeed seriously skewed in the direction of body parts), and (b) many of these words show morphological characteristics typical of Maba, not Maban, implying that they could have been borrowed "wholesale" from that language (on the other hand, some of those paradigms could simply be archaic).

Of course, there is also a third possibility, namely, that some or all of the body part terms, elicited by Nachtigal, were not actually "Mimi words" (i. e. words genetically inherited from previous generations, or words that were recently borrowed into the language from Maba, wiping out the original terms), but "Maba words", i. e. "polite" or otherwise "stylistically marked" synonyms that the speakers could, in certain situations, substitute for their native words - a situation not altogether unknown on the African continent. Such a solution would explain both the preponderance of words with Maban etymologies in the "body part term" category and their specifically Maba-like paradigmatic behavior. At the same time it would reduce strong evidence for the "Mimi(N)-Maban" family to more or less the same size as evidence for the "Mimi(D)-Maban" family, that is, close to zero.

Accepting this third solution for all of the isoglosses is, however, not very realistic: such terms as 'ear', 'eye', 'tooth', 'foot' are significantly different from their Maba equivalents (either segmentally or in relation to their paradigms), and, as has been suggested above, some of the other terms may simply have undergone Maba influence without necessarily having been

\footnotetext{
8 The fact that the "more stable" part of the 100-wordlist features but one fully reliable comparandum and the "less stable" part of it features two is also a formal violation of the "Yakhontov criterion" (originally proposed for a different split of the 100-wordlist, but well applicable to the current one as well): related languages / language families have to have more lexicostatistical matches in their "more stable" parts than in the "less stable" ones. Of course, it goes without saying that application of this criterion to such quantities of matches as one or two is, altogether, somewhat pointless.
} 
borrowed from that language. The decisive argument, to me, for sticking with the "Mimi(N)Maban" working model is that so few of the isoglosses, compared to Mimi-D/Maban, are exclusive Mimi-N/Maba parallels - a very significant distinction that has to have some bearing on the resulting classification.

Although, unfortunately, our knowledge on the grammatical features of both Mimis is close to non-existent, there are at least two (admittedly, very feeble) arguments that could also be used to prop up the idea of a genetic connection between Mimi-N and Maban:

1. The system of plural marking, employed in Mimi (a diverse set of mostly monovocalic suffixes that, in a seemingly unpredictable manner, either complement consonant-final stems or replace the vowel in vowel-final singulative stems), is much more similar to the one in Maban languages than to systems commonly observed in other "Nilo-Saharan" taxa in the area (e. g. Central Sudanic or Saharan).

2. The only known (or, rather, surmised) personal marker in the verbal system is the prefix $z$ - in imperative forms, presumably denoting the 2 nd $\mathrm{sg}$. person. This may be compared to one of the allomorphs of the 2nd sg. subject prefix in Maban (Mab z=, Msl, Aik, Kib $\breve{z}=$ ), although this is not really saying much, since this prefix is well-known to possess a whole multitude of allomorphs in Maban, and the issue of its reconstruction on the Proto-Maban level is wide open ${ }^{9}$.

What are the practical implications of these conclusions? First, that in any type of comparison that somehow deals with the "Nilo-Saharan" issue, it is absolutely imperative to discriminate between "Maban" and "Mimi", be it Mimi-D or Mimi-N; treatment of Mimi material on par with, say, Masalit or Aiki (as is done, for instance, in Ehret's [2001] etymological dictionary of Nilo-Saharan) is methodologically erroneous.

Second, evidence from Mimi-N at least must be kept "close in hand" during any attempts to establish the closest relatives of Maban within the large "Nilo-Saharan" complex. For instance, based on my current (so far, highly preliminary) lexicostatistical assessment of the data, it seems as if Maban may have a more special affinity with Central Sudanic than Eastern Sudanic. In testing this hypothesis, it will be interesting to assess the position of Mimi-N in between the relatively small Maban group and the huge Central Sudanic family. If it turns out that there are more "relationship signals" between Mimi-N and some other African taxon than between Mimi-N and Maban, our working hypothesis will have to be changed. For the moment, however, there is no evidence in favor of such a change.

Third and last, the situation that has just been described can, I believe, be of great interest to any comparative linguist, since our ability to establish a substantial historical difference between "Maban vs. Mimi-N" and "Maban vs. Mimi-D" turns out to be crucially dependent on a careful distributional study of the compared items in different languages. It is my firm belief that successful historical linguistics should amount to much more than simply grouping together sets of comparanda; each such set must be correlated with a realistic historical scenario, with the ensuing multitude of scenarios holding no mutual contradictions or typologically impossible absurdities. Thus, the complex historical scenario "Mimi-D is closely / distantly genetically related to / forms part of the Maban family" turned out to be full of contra-

${ }_{9}^{9}$ Wolff $[1989,1991]$ argues for an original ${ }^{*} m=$, based on analogies with the personal pronoun, but I find the argumentation exceedingly forced from a historical-phonological point of view, and would prefer to depart from an original glide $\left({ }^{*} y=\right)$ instead; this is, however, an entirely different topic, way beyond the scope of the current publication. 
dictions with much better established scenarios (internal developments within the Maban family), whereas the complex historical scenario "Mimi-N is a distant relative of the Maban family" holds much better against the available evidence, even if it is not entirely unproblematic in itself.

In fact, it may not be as important to be able to give a definitive, non-refutable yes/no type of answer as it is to be able to find an objective means of comparative evaluation of the evidence. The primary objective of this paper was to show that Nachtigal's Mimi is a better "proposition" for genetic relationship with Maban than Decorse's Mimi, not that Nachtigal's Mimi is "unquestionably related" to Maban. I sincerely hope that this objective has been reached.

\section{References}

Barth 1862 - Heinrich BARTH. Collection of vocabularies of Central-African Languages. Gotha: Justus Perthes.

Bender 1997 - Lionel M. BENDER. The Nilo-Saharan Languages: A Comparative Essay. München - Newcastle: LINCOM Europa.

Doornbos \& Bender 1983 - Paul Doornbos, M. Lionel Bender. Languages of Wadai-Darfur // Nilo-Saharan Language Studies. Ed. by M. Lionel Bender. Michigan: East Lansing, pp. 42-79.

Edgar 1989 - John T. EDGAR. A Masalit Grammar (with notes on other languages of Darfur and Wadai). Berlin: Dietrich Reimer Verlag.

Edgar 1991a - John T. EdGAR. Maba-Group Lexicon. Berlin: Dietrich Reimer Verlag.

Edgar 1991b - John T. EdGAR. First Steps Toward Proto-Maba // African Languages and Cultures 4, 2, pp. $113-133$.

Ehret 2001 - Christopher EHRET. A Historical-Comparative Reconstruction of Nilo-Saharan. Köln: Rüdiger Köppe Verlag.

Ethnologue 2009 - Ethnologue: Languages of the World. 16th edition. Dallas: SIL International. On-line version: http://www.ethnologue.com.

Gaudefroy-Demombynes 1907 - M. GAUDEFROY-DEMOMBYNES. Documents sur les langues de l'Oubangui-Chari // Actes du XIV. Congrès des Orientalistes (Alger 1905), vol. 2. Paris, pp. 264-277.

Greenberg 1950 - Joseph H. GREENBERG. Studies in African linguistic classification: VII. Smaller families; index of languages // Southwestern Journal of Anthropology, 6, pp. 388-398.

Greenberg 1966 - Joseph H. GREEnBERG. The Languages of Africa. Bloomington, Indiana University; Mouton \& Co., The Hague.

Greenberg 1971 - Joseph H. GREENBERG. Nilo-Saharan and Meroitic // Linguistics in Sub-Saharan Africa. Current Trends in Linguistics, Vol. 7. Ed. by Thomas A. Sebeok. The Hague - Paris: Mouton, pp. 421-442.

Greenberg 1972 - Joseph H. GreEnBERG. On the identity of Jungraithmayr's Mimi // Africana Marburgensia, 5, 2, pp. 45-49.

Jungraithmayr 1971 - Hermann JungraithMAYR. How many Mimi languages are there? // Africana Marburgensia, 4, 2, pp. 62-69.

Lukas 1933 - Johannes LuKAS. Beiträge zur Kenntnis der Sprachen von Wadai // Journal de la Société des Africanistes, pp. 25-56.

Lukas 1952 - Johannes LuKAs. Verbalwurzel und Verbalaffixe im Maba // Afrika und Übersee 36, pp. 93-98.

Lukas 1953 - Johannes LUKAS. Tonbezeichnete Mabatexte (Waddai) // Afrika und Übersee 37, pp. 51-60.

Lukas \& Völckers 1939 - Johannes LUKAS, O. VÖLCKERS. G. Nachtigal's Aufzeichnungen über die Sprache der Mimi in Wadai // Zeitschrift für Eingeborenen-Sprachen, 39, 2, pp.145-154.

Mbernodji \& Wolf 2008 - Calvain MBERnODJI, Katharina Wolf. Une Enquête Sociolinguistique des Parlers Kibet, Rounga, Daggal et Mourro du Tchad. Rapport technique. SIL International.

Nachtigal 1879-89 - Gustav NACHTIGAL. Sahara und Sudan. Ergebnisse sechsjähriger Reisen in Afrika, I-III. Berlin.

Nougayrol 1986 - Pierre NougAYROL. Note sur la langue kibet (Tchad) // Africana Marburgensia, XIX, 2, pp. 38-55.

Nougayrol 1989 - Pierre Nougayrol. La langue des Aiki dits Rounga. Esquisse descriptive et lexique. Paris: Paul Geuthner.

Rottland 1982 - Franz RotTLAND. Die Südnilotischen Sprachen: Beschreibung, Vergleichung und Rekonstruktion. Berlin: Dietrich Reimer Verlag. 
Starostin 2010 - George StAROstin. Preliminary lexicostatistics as a basis for language classification: a new approach // Journal of Language Relationship, v. 3, pp. 79-117.

S. Starostin 2004 - Sergei A. STAROSTIN. Opredeleniye ustoichivosti bazisnoy leksiki [Definition of stability of the basic lexicon] // S. A. STAROstin. Trudy po yazykoznaniyu [Works in linguistics]. Moscow, Yazyki slavyanskikh kul'tur, 2007, pp. 827-839.

Trenga 1947 - G. TRengA. Le bura-mabang du Ouadaï: notes pour servir à l'étude de la langue Maba. Paris: Travaux et Mémoires de l'Institut d'Ethnologie, 49.

Tucker 1940 - A. N. TUCKER. The Eastern Sudanic Languages. Volume I. London-New York-Toronto: Oxford University Press.

Tucker \& Bryan 1956 - A. N. TUCKER, M. BRYAN. The Non-Bantu Languages of North-Eastern Africa. Oxford University Press.

Tucker \& Bryan 1966 - A. N. TUCKER, M. Bryan. The Non-Bantu Languages of North-Eastern Africa: Linguistic Analyses. Oxford University Press.

Vossen 1982 - Rainer VossEN. The Eastern Nilotes: Linguistic and Historical Reconstructions. Berlin: Dietrich Reimer Verlag.

Wolf 2010 - Katharina Wolf. Une enquête sociolinguistique parmi les Amdang (Mimi) du Tchad. Rapport Technique. SIL International.

Wolff 1989 - Ekkehard WolfF. Morphophonology of the Verb-Initial Consonant in Maba // Topics in Nilo-Saharan Linguistics. Ed. by M. Lionel Bender. Hamburg: Helmut Buske Verlag, pp. 67-84.

Wolff 1991 - Ekkehard WolfF. On the Morphology of the Verb-Initial Consonant in Maba (Nilosaharan) // Proceedings of the Third Nilo-Saharan Linguistics Colloquium. Kisumu, Kenya, Aug. 4 - 9, 1986. Ed. by F. RoTTLAND \& L. M. OMONDI. Hamburg: Helmut Buske Verlag, pp. 277-285.

Статья посвящена неразрешенному вопросу о генетической принадлежности т. н. «языков мими» - двух отдельных наречий, лексические данные по которым были собраны более ста лет тому назад в северноафриканских областях Вадай и Дарфур (существует еще и третий язык «мими», открытый позже, однако его почти сразу же удалось опознать как близкого родственника хорошо известного языка фур). Большинство исследователей вслед за Дж. Гринбергом склонны считать ближайшим родственником обоих этих языков группу маба; однако тщательный анализ лексических данных, с упором на дистрибутивные и этимологические характеристики предполагаемых когнатов в языках маба, показывает, что только для одного из этих языков («мими Нахтигаля») гипотезу о родстве (при этом не очень близком) с маба можно принять в качестве рабочей гипотезы. Что касается второго языка («мими Декорса»), то его отношения с языками маба уместнее интерпретировать как контактно-ареальные, а решение вопроса о его генетической принадлежности следует отложить вплоть до прояснения общей ситуации с составом и внутренней классификацией нило-сахарской макросемьи.

Ключевые слова: нило-сахарские языки, языки мими, языки маба, лексикостатистика, классификация языков, сравнительно-исторический метод, языковое родство, список Сводеша. 